\title{
Article \\ A Study on the Integration of Resilience and Smart City Concepts in Urban Systems
}

\author{
Anastasia Tzioutziou (D) and Yiannis Xenidis *(D) \\ Department of Civil Engineering, Aristotle University of Thessaloniki, University Campus, \\ 54124 Thessaloniki, Greece; tzioutzi@civil.auth.gr \\ * Correspondence: ioxen@civil.auth.gr
}

Citation: Tzioutziou, A.; Xenidis, Y. A Study on the Integration of Resilience and Smart City Concepts in Urban Systems. Infrastructures 2021, 6, 24. https://doi.org/ $10.3390 /$ infrastructures6020024

Academic Editor: Ahmed W.

A. Hammad

Received: 31 December 2020

Accepted: 29 January 2021

Published: 4 February 2021

Publisher's Note: MDPI stays neutral with regard to jurisdictional claims in published maps and institutional affiliations.

Copyright: (c) 2021 by the authors. Licensee MDPI, Basel, Switzerland. This article is an open access article distributed under the terms and conditions of the Creative Commons Attribution (CC BY) license (https:// creativecommons.org/licenses/by/ $4.0 /)$.

\begin{abstract}
The continuous growth of cities brings out various concerns for improved development and management of the multifaceted urban systems, including those of resilience and smartness. Despite the many significant efforts in the research field, both notions remain changeable, thus retaining the lack of commonly accepted conceptual and terminological frameworks. The paper's research goals are to designate the current direct and indirect links in the conceptualizations and research trends of the resilience and smart city frameworks and to prove the potential of the conceptual convergence between them in the context of urban systems. The application of a semi-systematic literature review, including bibliometric evidence and followed by content analysis, has led to the observation that as the resilience discourse opens up to embrace other dimensions, including technology, the smart city research turns its interest to the perspective of urban protection. Therefore, both concepts share the goal for urban sustainability realized through specific capacities and processes and operationalized with the deployment of technology. The paper's findings suggest that the conceptual and operational foundations of these two concepts could support the emergence of an integrated framework. Such a prospect acknowledges the instrumental role of the smart city approach in the pursuit of urban resilience and unfolds a new model for sustainable city management and development.
\end{abstract}

Keywords: resilience; smart city; emergent property; urban development; infrastructure; sociotechnical system

\section{Introduction}

For the last 20 years, the concepts of resilience and smart city have been addressed as frameworks for infrastructure and urban development, and the respective research and applications have established new requirements and new perspectives for the built environment. Baron [1] suggested that the two concepts are "operationalized on the basis of similar or even the same systems, having similar trajectories of development and similar dilemmas to be solved". While, normally, the two concepts should be interlinked or, at least, converge, both a simple reading of the concepts' definitions and the literature findings [2-4] prove otherwise. This situation may be, largely, attributed to the fact that both concepts, obviously, are not determined in a definitive and clear way, despite the many respective efforts. The popular notion of resilience conveys so many different interpretations, that the actual meaning of the term is still unclear [5]. Likewise, while the smart city has become a trend in the field of urban development [6-8], the understanding of the term remains obscure $[4,9]$. At the same time, the necessity to integrate the two concepts at the operational level towards a transition from conventional, vulnerable, and mismanaged urban built environments to smart, sustainable, and resilient ones has just recently started to emerge $[4,10]$. It is interesting that only a few research projects have already explored the resonance between the smart city and the resilience frameworks in real urban systems. Such examples are the city of Florence in Italy, where researchers employed applications of smart technology to monitor the levels of urban resilience [11], and the city quarter Bahnstadt of Heidelberg in Germany, where researchers aimed to model the vulnerabilities and 
the overall resilience in the context of the smart city [12]. At a nation-wide scale, $\mathrm{Zhu}, \mathrm{Li}$, and Feng [13] aimed to evaluate the resilience of 187 Chinese smart cities and highlighted the cities of Shenzhen, Beijing, Shanghai, and Guangzhou as the most successful examples of smart and resilient urban development. All these, demonstrate the existence of a vague epistemic background, which hinders from the integration of the two concepts despite the implied potential and the operational need for such a development. The research hypothesis in this paper is that the potential for convergence between the two concepts in the context of urban systems lies in the direct and indirect links between the fundamental conceptual parameters of the two contexts. Consequently, the research goal in this paper is to designate these parameters and prove the potential of the conceptual convergence between the resilience and smart city frameworks based on the evidence that literature review provides on the emerging common theoretical framework of urban resilience and smartness.

The paper is organized in the following way: Section 2 presents the applied methodology in the context of this research. Section 3 provides the findings for the framework of resilience, its current conceptualizations and the emerging perspectives, while Section 4 presents the corresponding findings for the smart city framework. Then, Section $5 \mathrm{em}-$ phasizes on the compatibility of the two approaches towards the emergence of a common conceptual framework. Finally, the conclusions of this work are presented in Section 6.

\section{Research Methodology}

The research design comprised three phases as shown in Figure 1, namely the review of the resilience concept, the review of the smart city concept, and the identification of the potential for integration of the two concepts in a common framework.

The research methodology for the first two phases was similar and was applied through the following steps:

(1) Setting the hypothesis and goals for the literature review. This step addressed the hypothesis that certain fundamental parameters exist for the conceptual definition of the studied framework. The goal of this phase was to identify these parameters and their theoretical evolution through published previous works.

(2) Conduct a thorough literature review in the respective field (i.e., resilience and smart city). This step aimed at providing the required pool of literature sources that could be studied to confirm or discard the hypothesis set in the previous step and achieve the targeted goal. A semi-systematic review process was selected based on this approach's appropriateness when exploring patterns in loosely defined fields, while at the same time seeking for an insight to the progress of development of these fields [14].

(3) Perform content analysis on the data collected from the literature review. Content analysis is a typical analysis of data drawn from semi-systematic reviews [14] and it supports the preliminary identification of main aspects of interest in the literature review process.

(4) Proceed with text-data mapping and a high-level bibliometric analysis of the results drawn from the content analysis to provide a solid documentation of the fundamental parameters of the conceptual framework under study and the detection of emerging research trends in the field.

The reviewed relative sources span the ten years period from 2010 to 2019, and they were traced through search over several databases with the use of appropriate keywords. The pool of sources for the resilience framework included a total of 114 publications, while for the smart city framework, the literature review included 109 publications. Following the distinct mapping of the two frameworks and the identification of an initial linkage between the smart city research and the resilience approach, the emerging conceptual convergence had to be examined vice versa. Therefore, in the third phase of the research methodology the concepts of smart city and smartness were searched in publications related to resilience, in order to explore the convergence of the two conceptual approaches based on bibliometric 
evidence of the literature in the field of resilience and previous results of emerging research trends. The results of all analyses are rigorously presented in Section 3.

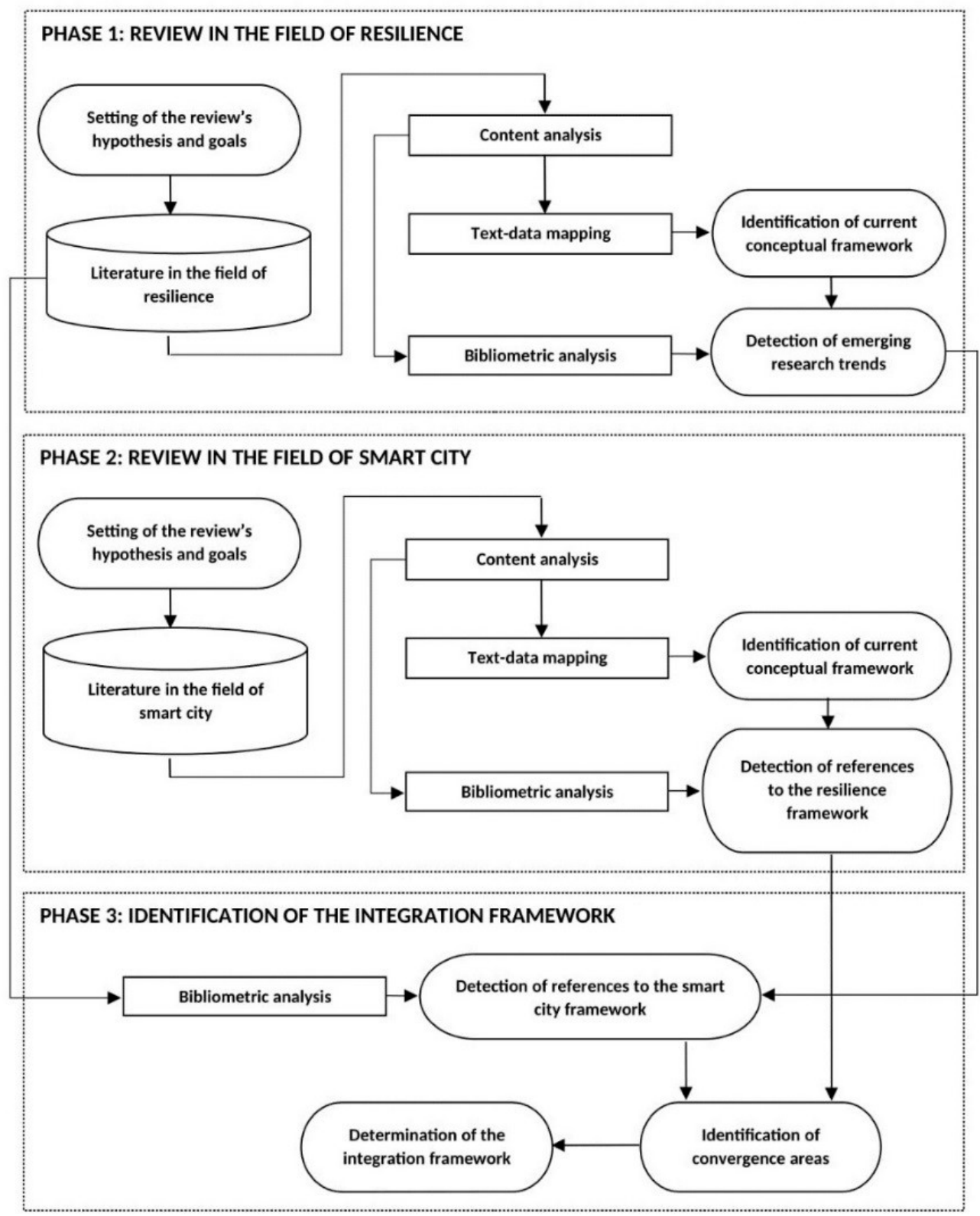

Figure 1. Research methodology.

\section{Analysis and Results: The Framework of Resilience}

A decisive factor to interpret "resilience" is the context of reference, and this is presumably the main reason behind the lack of a clear and shared understanding of the term in the entire research community. Consequently, the first goal of the analysis was to identify the current conceptualizations of resilience. A second goal was to trace the research trend towards the association of resilience with notions, which are frequently met in the respective literature as determinants of the term's contextual framework, yet not in a standard manner, thus creating a varying interpretation of the term in different periods. These notions are namely the complexity, technology, learning, and sustainability. The results from those analyses are put together in Section 3.3 to describe the context wherein the emerging definition for the concept of resilience lies. 


\subsection{Current Conceptualizations of Resilience}

As already stated, the current literature clearly shows the lack of an overall consensus on the definition of resilience, especially across the different contexts of application. Resilience is largely considered as a compound theoretical framework to describe a system's performance before, during, and after a disruptive event and thus, it is described as a complex conceptual construct that can integrate effectively many notions. The literature review underlined a range of notions, which are practically employed for the definition of resilience, in order to reflect the diverse conceptualizations. The employment of these notions in the examined publications, frequently follows a pattern of using two levels for the definition of resilience. At the first level, notions with more generic meaning tend to be employed, such as the terms "property" and "ability", which describe the core concept of resilience. Then, at a second level, other terms are engaged in the conceptual construct, such as "process", "capacity", and "capability", which reflect more context-related specifications.

Throughout the examined literature and regardless of the application field, the generic notion of property is steadily used to describe the concept of resilience by academia [15-18], organizations [19], and industry bodies [20]. Likewise, the term "ability" also conveys a generic meaning and consequently is effectively employed by diverse scientific disciplines, according to many researchers [21,22] and established organizations [19,23]. On the other hand, the conceptualization of resilience as a process is complementary to the aforementioned frameworks, mainly with the purpose of operationalization [12,24-27]. A similar condition is observed for the notions "capacity" and "capability", which are employed in more context-specific theoretical frameworks. In particular, the term "capacity" conveys a specific understanding derived from the context of socio-ecological resilience and is strongly related with the notion of adaptation [28], while "capability" is more related with the context of social structures [29]. This pluralism in the existing terminological framework depicts the ambiguities and the conceptual controversies, which are embedded in the current resilience thinking.

The definition of resilience as seen in the context of a system's recovery from disruptions is characterized as a descriptive concept of ecological systems that portrays its functions [30]. On the other hand, it is possible to interpret resilience as a way of understanding systems' interactions [31], which clearly implies the concept's perception in a normative manner [32]. This contrast in the interpretations reflects the various levels of emphasis or the difficulty to distinguish the limits (or both) between conservation and evolution for a given system, two states, which coexist in the context of resilience and their antagonistic nature is captured in multiple conceptual controversies in the respective literature. A prevailing interpretative dichotomy regards the consideration of a single equilibrium state opposed to consecutive cycles of adaptation that presuppose the existence of multiple equilibria $[21,31,33,34]$. This controversy essentially highlights a fundamental dipole of the resilience framework, that of stability and transformation, which is also identified in several contradicting pair of notions, like robustness and flexibility [5,35], or interdependency and interconnectedness [36].

The interpretative duality between a stable conservation and a transformative evolution is also evident in the dichotomy between a "result-oriented" versus a "processoriented" understanding of resilience, [24], which is essential not only to examine the causality or the normativity of a resilient system [37], but also to determine its static and dynamic prospects. According to Forsyth [38], resilience can be coined as the outcome of a given transformation process, a definition implying that both conceptions are effectively integrated in the resilience thinking.

A possible explanation for this duality is that resilience can be achieved in various ways and at different levels in a system, according to given circumstances and conditions. Therefore, it is assumed that a system cannot be completely resilient, but instead it is possible to increase the resilience of specific facets of the system, while other facets remain more vulnerable [5]. So, depending on specific systemic characteristics and the disruption 
scenarios, resilience can be conditionally expressed through diverse qualities that pertain to an entire spectrum of conceptual aspects, ranging from stability to transformation.

\subsection{Notions Frequently Associated with Resilience}

The notion of resilience is a wide and yet flexible theoretical framework that may encompass a variety of different aspects, according to the given application context. During the last 20 years, though, the extensive resilience discourse on both theoretical and operationalization frameworks revolves around some specific issues, which can be categorized into the four (4) broader theoretical notions of complexity, learning, technology and sustainability. A number of 69 out of 114 publications refer to at least one of these notions representing the $62.28 \%$ of the total number of publications, while Figure 2 demonstrates the frequency of appearance of these notions in the examined literature.

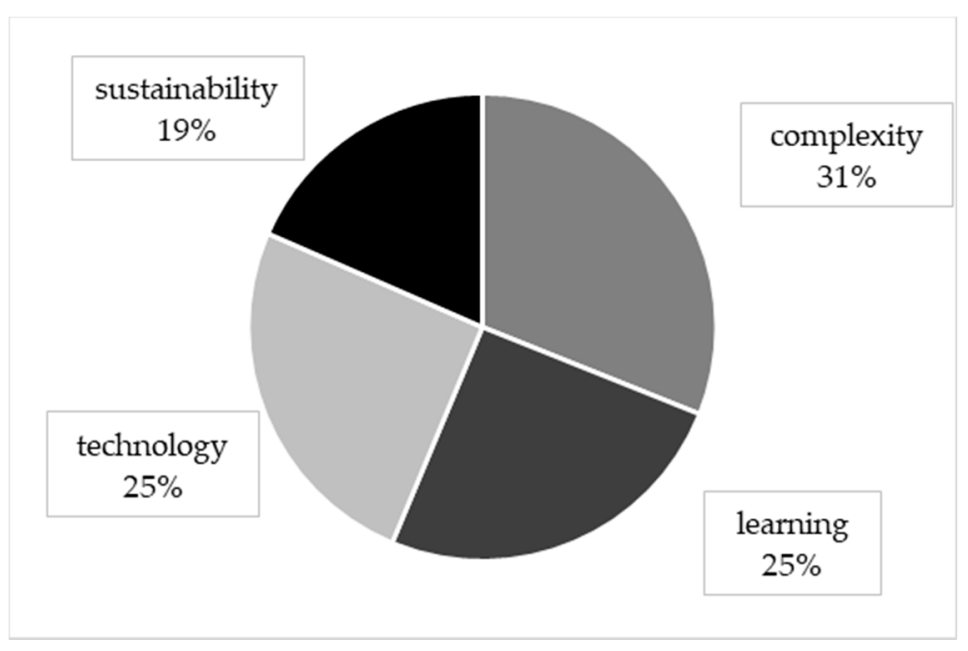

Figure 2. Distribution of the notions frequently met in association with resilience.

These four notions represent the different perspectives of the resilience research explored from the theoretical frameworks to the operationalization approaches. In detail, the research on resilience faces the issue of complexity, which is an inherent property of systems, and a challenging parameter of the explored reference framework. From a different point of view, the notion of learning is an integral part of the conceptual construct of resilience that relates, emphatically with the dimension of operationalization. The perspective of technology, on the other hand, adds a new dimension in the resilience research with the reconfiguration of systemic structures and with the provision of operationalization means. Technology can be considered as the tool to respond to the challenges derived from complexity and to exploit the opportunities from learning. Finally, the notion of sustainability refers mainly to the theoretical framework and reflects the effort to establish compatibility between the resilient and the sustainable development paths.

The investigation of these aspects has not been consistent through the years, but according to the evidence from the examined literature, it has followed different patterns of gradual development and evolution. Figure 3 presents this evolution towards the current multi-dimensional approaches of the resilience notion.

A first observation is that in the very short period of two years (2010-2012) the resilience discourse had addressed all four aspects starting with only few references to the notion of complexity and learning in 2010 that steadily grew until the introduction of the notions of sustainability and technology in 2012.

In the next two years (2012-2014) a feeble increase is observed in the number of references to these notions; however, after 2014 sustainability and technology are increasingly addressed until 2018, while after 2016 complexity and learning are also gaining attention again in the literature. Figure 3 reflects a standard process followed by the research community in establishing a new research field, which starts from the initial, yet adequate, field 
definition (2010-2012) and progresses with the debate between the new field's features and the existing paradigm's standards (2012-2014) [39]. Then, when the field is already better shaped, a more in-depth delineation initiates by scrutinizing the fundamental pillars of the new theory (2014-today). In this process, it is obvious that resilience is acknowledged as a multifaceted concept as researchers tend to examine simultaneously the identified aspects, thus supporting the argument of multidimensionality.

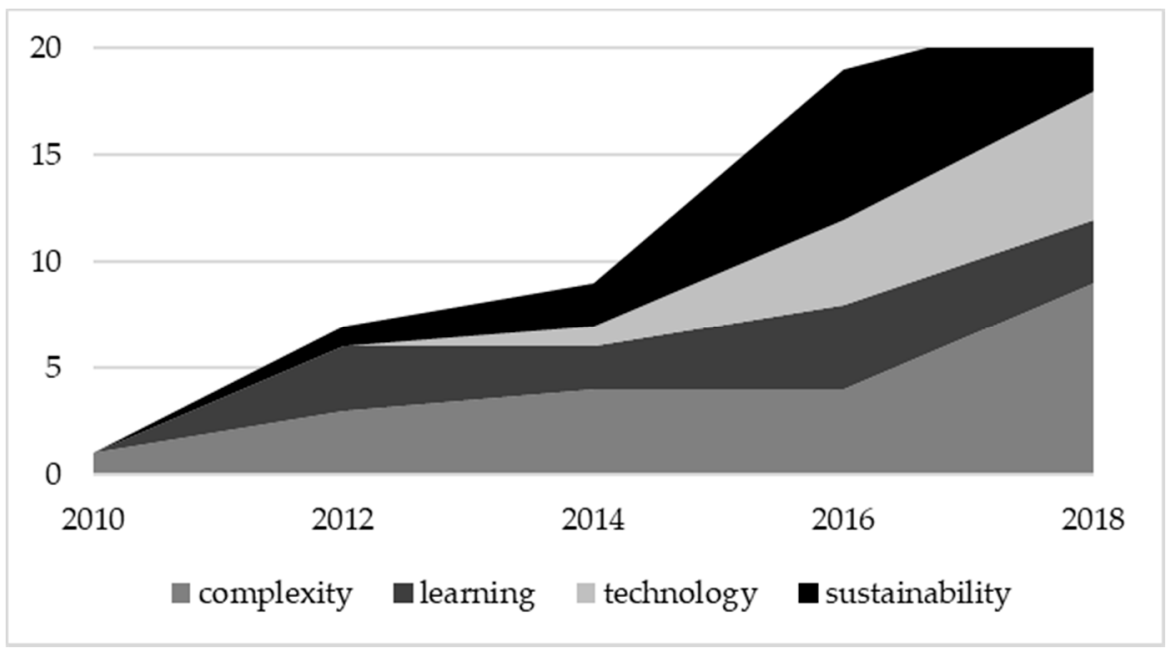

Figure 3. Evolution of the frequently met notions in association to resilience.

Last, Figure 3 suggests that the four notions are evenly gaining acknowledgement by the research community especially after 2016 when they seem to increasingly appear at almost the same pace. Sections 3.2.1-3.2.4 present in more detail the discussed notions of resilience.

\subsubsection{Complexity}

Complexity is the aspect of the notion of resilience, which is highlighted most often in the examined literature. This finding is reasonably expected, since the notion of resilience pertains to systemic structures and complexity is an inherent aspect of systems thinking. In many researches, there is a tendency to address the aspect of complexity $[5,40]$ especially in the context of socio-technical systems [12,41,42], while other researches give prominence to the existence of interdependencies, as the main feature of complexity that affects the overall systems' performance [43]. It is also argued that the notion of resilience captures the interconnectedness of a system [24,36].

The main challenge of complexity, though, is to frame the unknown mechanisms of the occurrence and propagation of interdependencies throughout the systems. Complexity is a systemic property that must be understood and properly addressed in order to enhance the effectiveness of resilience management [12,44]. In particular, Vollmer et al. [45] suggest that, compared to risk management that involves uncertainty and vulnerability, resilience management can additionally deal with the notion of complexity, to achieve a more effective and complete response to disturbed systems.

\subsubsection{Technology}

The advancements in both the theoretical field and the practical applications of the resilience notion can offer new potential to the respective research field and cause a twosided impact. On the one hand, the integration of technology increases the system's complexity, but on the other hand it is regarded as an enabling asset for the system.

Based on systems thinking, embedding technology to a system increases the interdependencies among systemic entities and possibly between different systems, leading to a vicious circle for the rise of complexity [46]. The integration of the Information and 
Communication Technologies (ICT) is regarded as a vulnerability factor and a threat for the system's resilience [10,47].

Nevertheless, several researches emphasize on the promising role of ICT in the resilience of the examined systems. These researches adopt a more technical perspective of resilience and tend to regard the incorporation of ICT in infrastructure systems as a beneficial integration for operationalization purposes [25-27,43,48,49] and particularly for optimization processes [15,50,51]. For example, Ferreira and Bellini [43] highlight the potential of information management for the enhancement of resilience, whilst Faturechi, Levenberg and Miller-Hooks [50] describe a decision support tool for the optimization of crisis management. In these efforts, it is assumed that technology is the only means that can tackle the intrinsic interdependencies of complex systems even at the expense of increasing the level of the systems' interconnectedness [52]. Moreover, the integration of technology in a system could enhance its overall performance by increasing the levels of efficiency, flexibility [15], and interoperability, and finally improving its capacity for learning [49]. Current information technology can facilitate, optimize, or even automate learning, enabling to reach higher levels of resilience [53].

\subsubsection{Learning}

Learning is another important perspective in the resilience research. Often described as a fundamental capacity of resilient systems, it is also included as a dimension for the operationalization of resilience $[5,16,35,54]$. The aspect of learning also captures the asset of community knowledge $[49,55]$, and most importantly the process of building new knowledge.

Almost complementary to learning is monitoring, namely the system's process to collect the necessary data over its performance [5]. Monitoring is primarily conceived as a core capacity of resilient systems [5], while it is also regarded as a main input especially for information and service systems, which function as autonomous or auxiliary networks [40].

A very important perspective of learning, connected to the evolution of socio-economical systems, regards innovation $[54,56]$. Innovation, which is connected to the notion of resilience [37] is also linked with the development of technology, and, also, regarded as an aspect of social welfare, contributing to sustainable development and adaptability [34]. With a focus on the process rather than the impacts, Coaffee et al. [54] conceptualize innovation as a property of resilience, while Annarelli and Nonino [29] consider it as an enabler for resilience. The capacity to innovate is considered as an important step for the building of system's resilience [33,41], since innovation is strongly connected to adaptation [56].

\subsubsection{Sustainability}

The notion of sustainability is fundamental for the most recent research approaches to resilience, particularly when the systems' social dimension is explored. The two notions are related as they both express the "ecological modernization" and share the same principles. It is interesting that the aspect of sustainability is highlighted through the lens of connectivity, learning [24], and social innovation [55,57] that promote social engagement and the citizens' life quality $[18,19,31]$. The resilient city, on the other hand, is often regarded as a sustainable paradigm for urban management [58], governance [59], and social development [60].

The literature suggests that resilience is essentially conceived as an aspect of sustainability, a fact highlighted by the majority of the examined urban development frameworks. However, the compatibility of the two concepts should not be taken for granted [18], as the special contextual conditions and characteristics, such as the issue of interdependencies in complex systemic structures may lead to divergent directions. The epistemic vagueness and the uncertainty regarding their implementation, leads few researchers, like Randers et al. [61], to investigate more the compatibility between sustainability and resilience concerning their operationalization in the urban system's context. 


\subsection{The Emergence of a Revised Definition of Resilience}

The ongoing scientific discourse leads to the evolution in the understanding of resilience. The recent resilience definitions seem to become more inclusive and alleviate former conceptual controversies, by highlighting the notion's multifaceted nature. Resilience is currently understood, mainly, as an intrinsic property of an entire system, which is enabled on the occasion of a disturbance at different levels according to the system's internal features (structure, interdependencies, etc.) and external environment. Consequently, depending on the conditions, resilience balances dynamically between its diverse features and scales $[58,62]$ through many potential trade-offs [30]. It is now evident that under the prism of resilience pairs of antagonistic notions, like stability and adaptation represent two sides of the same coin.

The recent definitions of resilience share some common conceptual assumptions that indicate the emergence of a revised framework for the notion's understanding. Firstly, resilience is conceived as a complex property referring to the sum of the parts of the examined system $[17,27]$. Moreover, the current interpretations of resilience include all the relative systemic processes and qualities, while they incidentally explain the observed multiplicity of certain terms in the examined definitions. As a result of the above, despite the various theoretical backgrounds and the various suggested interpretations, a great number of experts from the technical to the social context, embraces the specific approach of considering resilience as an inherent collective systemic property $[17,26,27,63]$. A limited number of researchers so far has explicitly suggested that this inclusive understanding of resilience should be conceptually defined as an emergent property $[56,64,65]$. The conceptualization of the emergent property pertains to the Theory of Emergence, which served as foundation for systems thinking and the complexity theory [66].

In addition to the above, the investigation of the resilience concept, especially in the context of urban systems is based on the understanding and the modeling of the diverse systemic structures, which gradually adopt more complex and multidisciplinary approaches. Particularly, hybrid forms of systems, like the socio-technical systems [65] and the system of systems [67] are developed to capture the complexity of the existing urban structures and to integrate recognized self-organizing capabilities and functions $[5,56]$. However, in spite of the progress of the relative modeling approaches, an integrated resilience framework covering complexity and interdisciplinarity is still missing [62].

\section{Analysis and Results: The Framework of Smart City}

Although, initially, the concept of the smart city emerged as an idealistic and visionary approach for city development, several technological advancements, such as Artificial Intelligence and the Internet of Things (IoT), have forced the examination of the smart city framework in a pragmatic and operational basis. Section 4 presents and analyzes the main conceptualizations that are found in the recent literature, as well as the principal dimensions of the smart city research related to the urban challenges including the issue of city protection against various shocks and stresses. The presented analysis concludes with providing evidence of a new discourse towards a revised understanding of the framework of the smart city.

\subsection{Current Conceptualizations of Smart City}

As the cities worldwide continue to grow, the smart city concept can be recognized as a new and evolving cycle of urbanization that could determine decisively the urban form and life, introducing a new, more advanced, generalized socio-material transformation of cities [68]. According to the investigated literature, the term "smart city" is still regarded as a vague vision for the future of cities [69], despite the efforts made towards defining and determining a specific city model that would correspond to the increasing need for operationalization of the smart city. While it is argued that the term "smart city" provides a wider conceptual framework in which different dimensions are developed, practically it is, mainly, conceived as a city development model based on ICT applications [70]. 
Apart from the urban growth context, the literature review reveals that in many cases the concept of smart city is analyzed using the systems thinking approach [71-74] in order to deal effectively with the notions of complexity and interdependence. Moreover, a number of researchers embraces the system of systems model for analyzing the smart city [75,76], based on this architecture's ability to capture collective capacities like knowledge creation and adaptation.

Instead of exploring a debatable theoretical background, some researchers purposefully identify the essence of smart city in the integration of ICT solutions in the existing urban systems $[6,74,77-79]$. This approach acknowledges the enabling role of technology in the pursuit of smartness and hence, the incorporation of the so-called smart infrastructure in the existing urban systems could increase the latter's performance and quality, with benefits to businesses and citizens [72].

As the discourse on the smart city definition continues, in practice the concept evolves to become more holistic and to reach a generic understanding. This evolution has involved the conceptualization of smart city as an urban development policy $[8,80,81]$ that can be dynamically adjusted and implemented in the existing urban systems. Similarly, the deployment of smart solutions creates new prospects for urban management and turns research interest to the direction of smart city governance [82].

\subsection{Other Notions Associated with Smart City}

Over the last years, the research on the "smart" approach for urban development intensified and revealed a tendency to address additional aspects from different domains. In this context, it has been observed that the research turned to the response to urban challenges and to the corresponding theoretical backgrounds of urban systems protection and resilience. These trends are further presented in Sections 4.2.1 and 4.2.2, respectively.

\subsubsection{Response to Urban Challenges}

As demonstrated in Figure 4, the discourse about urban challenges, with the exception of one year (i.e., 2016), is constantly increasing in the current literature on smart cities and, according to the content analysis of the respective publications, this dimension integrates various different perspectives.

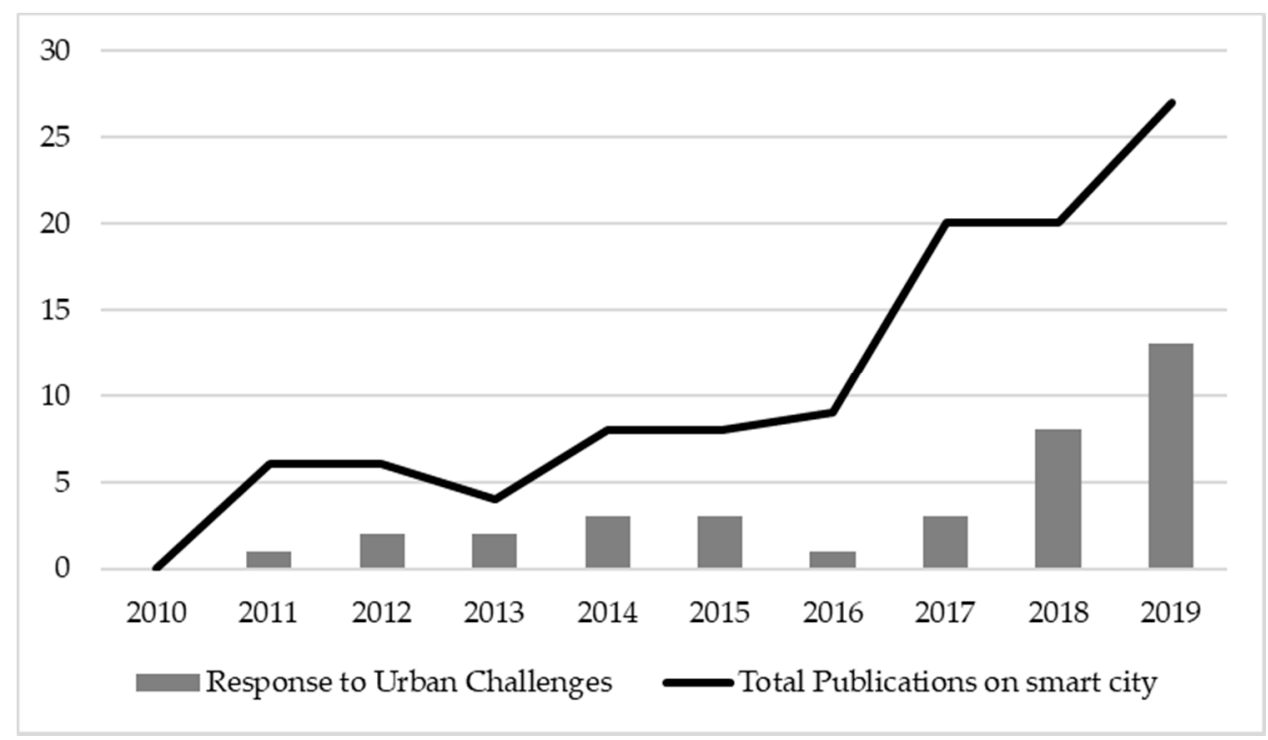

Figure 4. Evolution in references to urban challenges.

The smart city concept is believed to solve persistent problems of different sources or nature, often characterized as "wicked problems", ranging from technical, to social, and to economic contexts [8]. Another branch of relevant issues that smart cities are suggested to 
solve includes environmental problems and potentially the provision of opportunities for more sustainable development $[4,81,83]$, whilst an additional category focuses on issues deriving from the urbanization phenomenon $[7,84]$. Some researchers also identify as urban challenges that the smart approach can tackle, the diverse issues of urban safety and security that rise in the field of operational management [72,74].

The broadly acknowledged need for response to urban problems also entails some specific challenges, especially in the context of emergency. Particularly, in the cases of catastrophic events, when direct and effective responses are needed, the qualities of rapidity and early warning are required and the existence of a proactive emergency planning is underlined [76]. Of course, these specific prerequisites towards a successful response to shocks and stresses are related to comprehensive frameworks for urban safety and civil protection that incorporate the resilience approach. Official organizations, like the Joint Technical Committee of the International Organization of Standardization and the International Electrotechnical Commission (ISO/IEC JTC1) [76], embrace this approach of emergency response and make a direct reference to the concept of urban resilience.

The addressing of the above-mentioned urban problems in the smart city concept remains largely a generalized statement, with some exceptions that introduce several perspectives and courses of action. In more detail, there are researchers suggesting that smart solutions could enhance the operation of existing multidimensional urban systems [85], diminish the impacts of potential hazards [79], and offer new perspectives in urban governance through participatory management [73]. For Andreani et al. [86] it is clear that all the dynamic features that a smart city presents, when inserted into the existing urban systems, contribute effectively to the response to all these challenges.

\subsubsection{References to Protection, Resilience, and Related Properties}

The smart city discourse has recently started to address aspects of urban protection and especially, that of resilience, which offers the contextual framework for smart urban systems' response to the problems mentioned in Section 4.2.1. Either by tacitly linking smartness with properties of resilience, or by clear references to the notion itself, there is some evidence that smart city researchers start to consider the resilience context in their research. Figure 5 presents a graphical record of the references to the resilience context in the smart city's literature, wherefrom several interesting observations are feasible.

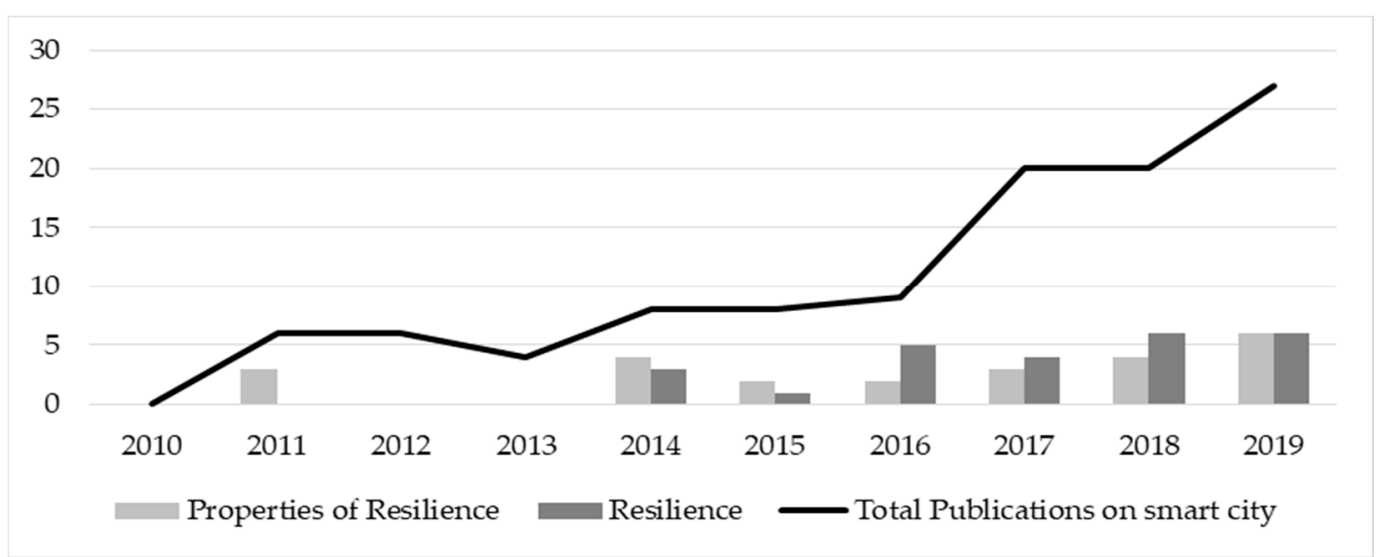

Figure 5. Number of smart city publications referring to the properties of resilience and the resilience term.

A first interesting note when comparing the numbers of publications addressing resilience in the field of smart cities to the respective number of total publications in the field is that there is no specific trend or equal growth of the resilience concept inside the smart city context. Based on the evidence, it seems that the research on smart cities has partially included the aspect of resilience, yet not as a trend or a topic that could attract more interest to the field's researchers compared to other topics. With reference to the 
number of publications that address resilience, Figure 5 also helps to observe that since 2017, there seems to be a more systematic introduction of the notion of resilience to the smart city field of research. Indeed, until then there is no pattern in the references to the notion of resilience or terms and topics that are directly related to it; however, after 2017, it seems that there is a systematization in the discussion of resilience in the context of smart city, wherein the notion of resilience and its features and properties are evenly addressed. Although the graph of Figure 5 examines the smart city publications that refer to the resilience term and to the properties of resilience as independent sets, it is observed that gradually the publications that refer to the concept of resilience, may also refer to the features of the resilience thinking. This finding might also reflect a better understanding of the resilience framework and a more conscious employment of it in the smart city research field.

The content analysis of the studied body of literature confirms the findings of the bibliometric approach. The discussion of resilience aspects from smart city experts is predominantly unsystematic and fragmented, especially until 2016. While there are suggestions about how the smart cities can improve certain capacities of urban systems connected to restoration processes, these suggestions are outside the resilience context. The discussion, also, of notions like recovery, rapidity, adaptation, and redundancy are, often, without direct references to the resilience approach [71], while proactive capacities inherently connected with the resilience framework, such as preparedness or self-organization, are presented as assets of the smart city concept $[71,75,86]$ without relating to the resilience context.

A beginning of change towards a more systematic discussion of resilience aspects becomes evident after 2017, when the evolutionary conceptualizations of city as an urban ecosystem, or the introduction of concepts like smart-sustainability, both being ideas that correspond to the ecological background of the resilience thinking, are growing to become quite common [84,87]. This development is aligned with the concurrent evolutionary approaches on urban development and proves that the smart city concept can be perfectly compatible with this broader theoretical framework.

Aside from the systematic incorporation of resilience aspects in the current smart city research, a direct embrace of resilience thinking as a context is, also noted after 2017. Experts who emphasize on the citizen-centered dimensions of smart city adopt a more holistic perspective and tend to refer more to the aspect of resilience. Following the earlier example of Kunzmann [88] who suggested that the smart city model can promote both the livability and the resilience of cities, there is a growing number of researchers who adopt a more generalized perspective and regard smart city as a hub that fosters both sustainability and resilience $[89,90]$. In this perspective, the concept of resilience is highlighted when the aspects of environmental sustainability are incorporated in the smart city discourse [91]. This allows the connection of smartness with the notion of resilience not only based on a technical background, but also on the socioeconomic and ecological aspects of urban systems.

In the same direction and by following a little differentiated conceptual approach, few experts refer directly to the model of "resilient city", as a comprehensive construct that integrates the principles and the ideals of smart city [4]. This point of view leads to the identification of the smart and resilient city models as labels and promotes the comparison between the respective development models, while it highlights the contradicting or complementary elements between the two approaches, according to different conceptual interpretations.

The investigation of smart city models under the prism of resilience allows, also, for a less popular and different perspective, which implies that the integration of smart solutions is harmful for the overall resilience of a city. Few researchers suggest that the incorporation of smart technology and the consequent rise of systemic interdependencies could diminish the resilience level of existing cities, especially in the social and the environmental con- 
text [77]. Nevertheless, the impacts of such interdependencies on system's resilience are still ambiguous and, thus, the researchers' views are not unanimous.

Overall, the trend of expanding the smart city context by embracing properties and capacities, and even complete conceptual constructs, which have been originally and extensively developed in other contexts, and especially the resilience context, brings out the need of a more holistic approach in the process of transformation to smart urban systems.

\subsection{Towards a Revised Definition of Smart City}

An evolving trend in the current smart city research is to focus on the property of smartness, rather than the more limiting perception of the urban development model. The emphasis on the attribute 'smart', as well as the prospect of a system to get 'smarter' [92] reveal the multidimensional conditionality and the comparative perspective of the concept. This conceptualization offers a more generalized and abstract understanding of 'being smart', with less context-specific and scale-related restrictions. According to some researchers "smartness" is coined as synonym of intelligence [93], while the majority of experts recognize it intuitively as a positive feature.

The most acknowledged element of smartness is undoubtedly the employment of ICT solutions, but certainly, it cannot be the only one. The idea of a 'smart city' that suggests a one-sided digitization has been widely accused for lack of purpose [94] and therefore, a meaningful idea is needed to refine this vision. In this context, the concept of smartness retains the positive connotation by providing an added value to each specific reference framework, connected with notions like efficiency, sustainability, and innovation in the context of complex socio-technical systems. Consequently, the malleable term 'urban smartness' describes an attribute or aspect of urban systems that could be easily integrated into other research frameworks. The new hybrid forms of city development models that emerge by the combination of smartness with other notions, like sustainability $[59,61]$ and resilience [2,31], are evidence of new integration frameworks, which, still, require more efforts towards their conceptual clarification.

\section{Analysis and Results: The Integration Framework}

The literature review and the corresponding analysis have clearly described, so far, the conceptual frameworks, the research dimensions and the development trends for the terms of resilience and smart city. Moreover, the findings of the research analysis clearly suggest that urban resilience and smartness are not two entirely independent concepts, but rather two complementary frameworks in the context of urban systems determined by gradually converging fundamental parameters that exist in both frameworks. This section argues on the emerging common ground of the two frameworks, first by providing evidence from the bibliometric analysis for the perspective of such a field and then, by presenting, based on content analysis, the specific constituents that determine the field of convergence and the type of relation between the two contexts.

\subsection{The Emerging Common Ground}

The recent progress in the understanding of the smart city context and specifically the conceptualization of smartness as a property revealed a new perspective for the convergence with the resilience thinking. The adjective "smart" is linked to efficiency, interconnectedness, and digitalization, referring to diverse scales, i.e., from a single circuit to an entire city. The qualities of smartness offer a new perspective, mainly in the operationalization of resilience in the socio-technical context. Particularly, according to Allam and Dhunny [95], the attributes of smart and resilient contexts are complementary in the pursuit of sustainable urban development. This is a reasonable assumption, since the employment of smart technology can improve various aspects of cities' processes and, consequently, promote urban resilience in terms of governance, economy, ecology, and overall quality of life [78]. 
Figure 6 presents graphically a feeble, yet steadily growing interest of researchers from 2010 to 2019, pertaining to the field of urban development and infrastructure systems that links resilience with smartness. The evidence from the examined literature, including the multiplicative power of research in emerging fields, shows that this trend is expected to continue in the near future.

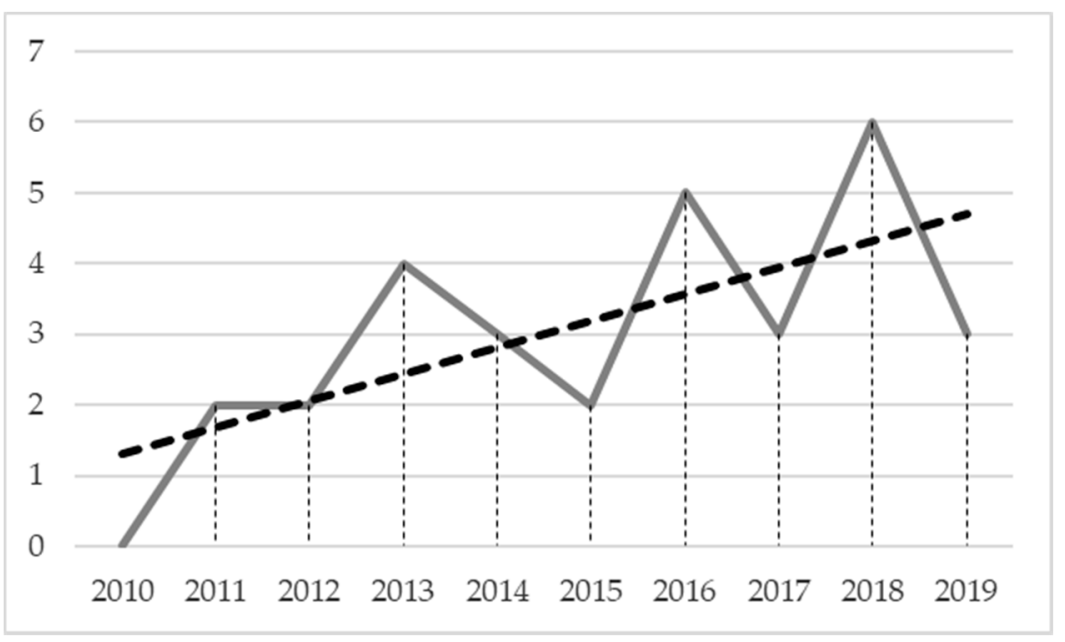

Figure 6. Evolution of resilience publications referring to aspects of smartness.

As illustrated by the trend lines in the diagram of Figure 7, there is a slightly increasing tendency among researchers of urban resilience to embrace primarily the approach of smart city, and secondarily the diverse aspects of smart urban systems, such as smart infrastructure or urban management. According to some of them, the employment of smart technology and smart infrastructure are requirements for the enhancement of urban resilience $[48,63,96]$. This desirable feature of smartness, which is related with urban resilience, refers to the dimension of urban governance and particularly, to the optimization of its operational deployment [16,59], while, according to economic perspectives, smartness can refer to the nexus urban growth that can foster resilience [21].

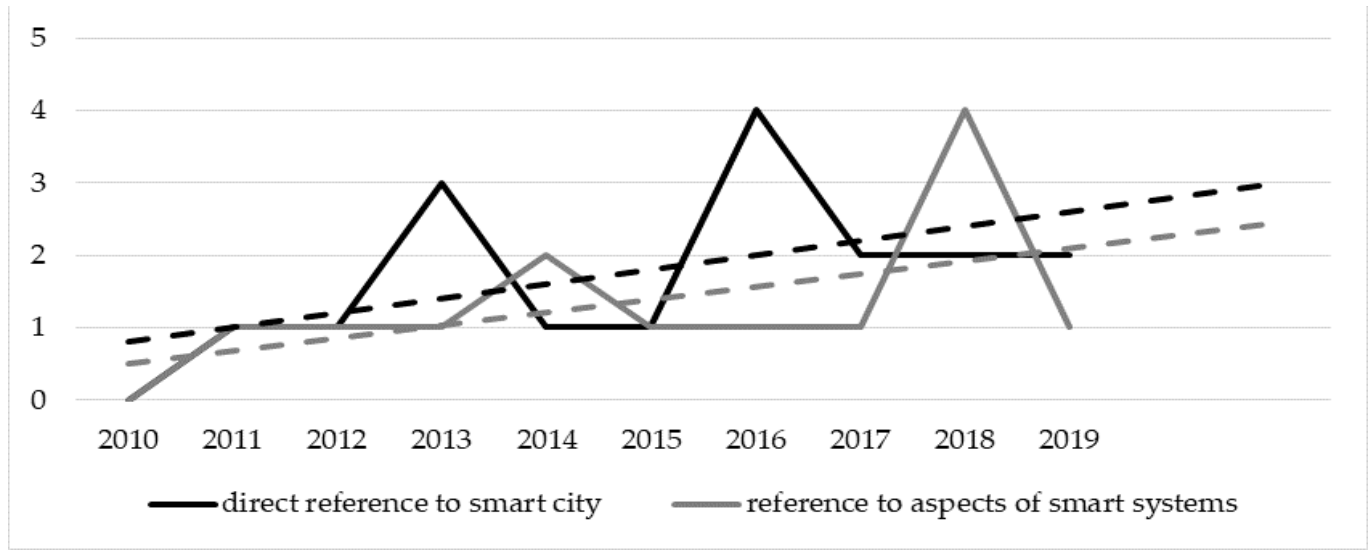

Figure 7. Evolution of resilience publications referring to the smart city concept (black colored lines) and the diverse aspects of smart systems (grey colored lines).

The research conducted in the first two phases revealed certain compatibilities between the smart city and the resilient city models, which prove the potential of a conceptual convergence between urban resilience and smartness, and set the ground for the conceptual and operational integration of the two frameworks. First of all, both conceptual frameworks refer to systemic structures that incorporate multiple and interdisciplinary facets. 
Especially for the context of urban systems, the employment of hybrid forms of systems that integrate technical and social dimensions, along with their interdependencies can serve the operational integration of the smart city model with the resilience approach. Additionally, the two concepts share the common goal of urban sustainability enhancement through the reduction in vulnerabilities and the improvement of life quality for citizens [31].

The above-mentioned operational integration is suggested from some researchers through reference to specific smart city aspects and their instrumental role in the enhancement of urban resilience $[48,97]$. Instead of integrating the different models of smart and resilient city into a new hybrid one, this approach focuses on the refinement of the smart city approaches through the prism of resilience [16]. The concept of resilience, with its wide spectrum, offers the theoretical framework to (re)define the purpose of interventions towards transforming a traditional city to a smart one. Similarly, the smart and digitalized infrastructure is the appropriate means to orchestrate the urban systems' response and adaptation after a disruption. For example, in this context, Ganin et al. [97] present the operational framework of a smart infrastructure system that can promote urban resilience.

Simultaneously, in the context of urban development, the concepts of the smart city and resilience feature common capacities and processes, which refer to innovation, learning, and self-organization, and are substantially promoted by technological developments. The invention and adoption of smarter tools is driven by the system's capacities for learning and innovation [44], which are also considered core capacities of resilience. Emphasizing on the property of smartness in the promotion of resilience, some researchers recognize the contribution of specific methods and tools of digital technology that mainly enhance the capacities of monitoring and learning [98] and promote the interaction between a network and its operators [22]. The smart technology offers new potential to some practical challenges like the identification and collection of valid operational inputs for resilience management, derived from monitoring [5,25] with appropriate BIM and GIS tools [27] and analytical models [99]. Additional technological advancements that already promote automation in monitoring include applications of Big Data management $[43,99]$ and IoT frameworks [51].

At the same time, the researchers who acknowledge the emerging conceptual and operational integration between urban resilience and smartness, cannot overlook the serious challenges that arise. Although the demand for the increase in urban resilience is unquestionable [100], the difficulty lies in the reconfiguration of the complex urban systems towards a new direction, determined by the anticipatory logic to support the features of preparedness and adaptation [101]. This required shift of focus to these features is characterized as a challenge for the existing smart city framework [100,101]. Moreover, the extensive employment of smart systems includes a negative side pertaining to the increased level of complexity and interdependency [12]. Since the proliferation of these systemic structures is now a fact, it is important to identify their overall impact on a given system's resilience.

\subsection{The Convergence of the Two Concepts}

According to the research's findings, there are multiple aspects of convergence between urban resilience and smartness that support the integration, conceptually and operationally, in a unified single framework. Starting from complexity, the need to incorporate the dimensions of protection and adaptation [2], as expressed in the resilience context, is recognized in the constantly evolving field of urban development. Urban resilience is now a requirement in the design and operation of city models, including smart cities, which is based on specific capacities, like adaptation, learning [102], response, and preparedness [103]. The emphasis on these core capacities highlights the compatibility of the smart concept with the principles of resilience.

In practice, systems thinking and the dimension of complexity serve as the shared operational framework for the urban development of the resilience and smart city concepts. Urban resilience can be promoted with the employment of conceptual constructs, such as 
the complex adaptive systems, which are also used to describe the development of smart city [6]. Furthermore, it is easy to detect the conceptual linkage of these two approaches in the perspective of sustainability and more specifically, for the reduction in vulnerability and the improvement of efficiency and overall quality of the urban systems. In fact, many smart city researchers that acknowledge the resilience concept claim that the employment of technology can enhance the capacities of any urban system [88] towards more resilient performance [82,103].

Another point of convergence between the concepts of smartness and resilience lies in the area of knowledge creation and management. Smart urban systems are prominent as structures built on networks of information and knowledge [103], but it is the multifaceted innovation, which is the most important moving force in this scheme [102]. At the same time, the ability to create knowledge, to solve problems in the process of adapting to given conditions reflects the main objectives of the resilience approach. Moreover, it can be assumed that, in terms of the examined socio-technical systems, innovation is an equivalent expression of adaptation in the context of complex urban challenges and therefore, the smart approach resonates with the resilience thinking. It is characteristic that, according to Marsal-Llacuna and Segal [104], in given contexts, the enhancement of the attribute of smartness leads to the enhancement of the entire system's resilience.

The solutions provided by the transformation to smart cities comprise some of the operational tools to achieve the required urban resilience. Since, smart city emphasizes on the improvement of urban operations and services, it essentially aims at the transformation of processes, rather at the actual infrastructural assets [100]. On the other hand, resilience refers to the further development of certain capacities [100], which derive as outputs of multiple interdependent and complex processes in the urban systems. Consequently, from this point of view, smart city is not only resonant with the concept of urban resilience, but an effective means to build relevant capacities as well. An interesting approach on the relationship between the smart and the urban resilience concepts implies that resilience is an intrinsic characteristic and that the technological solutions offer the means to promote it [70]. In this framework of understanding, smart technology is regarded as means for the pursuit of resilience, and therefore the smart city concept represents a context-specific and operational aspect of the generalized concept of resilience.

\section{Conclusions}

Despite the vagueness that characterizes the understanding of the resilience and the smart city concepts, they are increasingly employed together in several theoretical and operational studies; however, the framework of this integration is still unclear. The purpose of this research was to examine the potential of convergence between these two frameworks based on the definition of common ground and fundamental parameters that determine both frameworks. The review on the definitions of resilience revealed the conceptual malleability of the term, its understanding as an emergent property, and its integration with the notions of complexity, technology, learning, and sustainability. On the other hand, the review on the framework of smart city underlined the evolution of the concept from a particular model of urban development, to smartness, an intellectual property that characterizes the multiple interconnected dimensions of modern urban systems.

The analysis for the identification of the compatibility between the resilience and the smart city frameworks confirmed the hypothesis that the two frameworks share specific fundamental determinants that allow the development of a unified concept instead of two discrete approaches in the context of urban development. Both urban resilience and smart city concepts serve the goal of sustainability and share the operational framework of systems' thinking. Additionally, the systemic capacities of adaptation, efficiency and knowledge creation are common in the frameworks of urban resilience and smartness. However, based on the importance of the dimension of technology, the smart city model seems to play an instrumental role in the operationalization of resilience. This finding highlights the specific roles of the two concepts in the emerging integrated framework, 
where the resilience thinking is the theoretical background and the design requirement for the deployment of the smart city solutions.

Author Contributions: Conceptualization, A.T. and Y.X.; methodology, A.T.; validation, A.T.; formal analysis, A.T.; investigation, A.T.; resources, A.T. and Y.X.; data curation, A.T.; writing-original draft preparation, A.T.; writing - review and editing, Y.X.; visualization, A.T. and Y.X.; supervision, Y.X.; project administration, Y.X. All authors have read and agreed to the published version of the manuscript.

Funding: This research received no external funding.

Conflicts of Interest: The authors declare no conflict of interest.

\section{References}

1. Baron, M. Do We Need Smart Cities For Resilience. J. Econ. Manag. 2012, 10, 31-46.

2. de Jong, M.; Joss, S.; Schraven, D.; Zhan, C.; Weijnen, M. Sustainable-Smart-Resilient-Low Carbon-Eco-Knowledge Cities; Making Sense of a Multitude of Concepts Promoting Sustainable Urbanization. J. Clean. Prod. 2015, 109, 25-38. [CrossRef]

3. Khan, S.; Zaman, A.U. Future Cities: Conceptualizing the Future Based on a Critical Examination of Existing Notions of Cities. Cities 2018, 72, 217-225. [CrossRef]

4. van den Buuse, D.; Kolk, A. An Exploration of Smart City Approaches by International ICT Firms. Technol. Forecast. Soc. Chang. 2019, 142, 220-234. [CrossRef]

5. Lundberg, J.; Johansson, B.J. Systemic Resilience Model. Reliab. Eng. Syst. Saf. 2015, 141, 22-32. [CrossRef]

6. Colding, J.; Barthel, S. An Urban Ecology Critique on the "Smart City" Model. J. Clean. Prod. 2017, 164, 95-101. [CrossRef]

7. Yigitcanlar, T.; Kamruzzaman, M. Smart Cities and Mobility: Does the Smartness of Australian Cities Lead to Sustainable Commuting Patterns? J. Urban Technol. 2018, 26, 21-46. [CrossRef]

8. Michalec, A.O.; Hayes, E.; Longhurst, J. Building Smart Cities, the Just Way. A Critical Review of "Smart" and "Just" Initiatives in Bristol, UK. Sustain. Cities Soc. 2019, 47, 101510. [CrossRef]

9. Sarma, S.; Sunny, S.A. Civic Entrepreneurial Ecosystems: Smart City Emergence in Kansas City. Bus. Horiz. 2017, 60, 843-853. [CrossRef]

10. Cassotta, S.; Sidortsov, R. Sustainable Cybersecurity? Rethinking Approaches to Protecting Energy Infrastructure in the European High North. Energy Res. Soc. Sci. 2019, 51, 129-133. [CrossRef]

11. Bellini, E.; Nesi, P.; Bellini, P. Information Model and Interopreability; RESOLUTE Project; D4.4; University of Florence: Florence, Italy, 2017.

12. Jovanovic, A.; Jelić, M.; Rosen, T.; Klimek, P.; Macika, S.; Øien, K. The ResilienceTool" of the SmartResilience Project; SmartResilience project; D3.7; EU-VRi: Stuttgart, Germany, 2019.

13. Zhu, S.; Li, D.; Feng, H. Is Smart City Resilient? Evidence from China. Sustain. Cities Soc. 2019, 50, 101636. [CrossRef]

14. Snyder, H. Literature Review as a Research Methodology: An Overview and Guidelines. J. Bus. Res. 2019, 104, 333-339. [CrossRef]

15. Davis, J.; Uffer, S. EVOLVING CITIES Exploring the Relations between Urban Form Resilience and the Governance of Urban Form; London School of Economics and Political Science: London, UK, 2013.

16. Heeks, R.; Ospina, A. Understanding Urban Climate Change and Digital Infrastructure Interventions from a Resilience Perspective; Development Informatics: Manchester, UK, 2013. [CrossRef]

17. Tamvakis, P.; Xenidis, Y. Comparative Evaluation of Resilience Quantification Methods for Infrastructure Systems. Procedia Soc. Behav. Sci. 2013, 74, 339-348. [CrossRef]

18. Redman, C.L. Should Sustainability and Resilience Be Combined or Remain Distinct Pursuits? Ecol. Soc. 2014, 19. [CrossRef]

19. UNISDR. How to Make Cities More Resilient A Handbook for Local Government Leaders; Molin Valdés, H., Rego, A., Scott, J., Valdés Aguayo, J., Bittner, P., Eds.; United Nations: Geneva, Switzerland, 2012.

20. Schneider Electric. Urban Efficiency as the Cornerstone of Attractive Cities; Schneider Electric: Rueil-Malmaison, France, 2018.

21. Drobniak, A. The Urban Resilience-Economic Perspective. J. Econ. Manag. 2012, 10, 5-20.

22. Øien, K.; Jovanovic, A.; Grøtan, T.; Choudhary, A.; Øren, A.; Tetlak, K.; Bodsberg, L.; Jelic, M. Assessing Resilience Level of Smart Critical Infrastructures Based on Indicators; SmartResilience Project; D3.8; EU-VRi: Stuttgart, Germany, 2018.

23. IPCC. Managing the Risks of Extreme Events and Disasters to Advance Climate Change Adaptation. A Special Report on Working Groups I and II of the Intergovernmental Panel on Climate Change; Field, C., Barros, V., Stocker, T., Dahe, Q., Eds.; Cambridge University Press: New York, NY, USA, 2012.

24. Kallaos, J.; Mainguy, G.; Wyckmans, A. Considering Resilience: Steps Towards an Assessment Framework. Tema J. Land Use Mobil. Environ. 2014, 7, 5-28. [CrossRef]

25. Lange, D.; Malm, A.; Mindykowski, P.; Alheib, M.; Bouffier, C.; Cauvin, L.; Willot, A.; Ioannou, I.; Rød, B. Technological Resilience Concepts Applied to Critical Infrastructure; Honfii, D., Ed.; SP Technical Research Institute of Sweden: Borås, Sweden, 2017.

26. Ramirez-Marquez, J.E.; Rocco, C.M.; Barker, K.; Moronta, J. Quantifying the Resilience of Community Structures in Networks. Reliab. Eng. Syst. Saf. 2018, 169, 466-474. [CrossRef] 
27. Rus, K.; Kilar, V.; Koren, D. Resilience Assessment of Complex Urban Systems to Natural Disasters: A New Literature Review. Int. J. Disaster Risk Reduct. 2018, 31, 311-330. [CrossRef]

28. Luskova, M.; Titko, M.; Bianchizza, C.; Prak, P. Methodology for Measuring Societal Vulnerability Due to Failure of Critical Land Transport Infrastructure Elements; RAIN Project; D3.4; University of Žilina: Zilina, Slovakia, 2017.

29. Annarelli, A.; Nonino, F. Strategic and Operational Management of Organizational Resilience: Current State of Research and Future Directions. Omega 2016, 62, 1-18. [CrossRef]

30. Meerow, S.; Newell, J.P.; Stults, M. Defining Urban Resilience: A Review. Landsc. Urban Plan. 2016, 147, 38-49. [CrossRef]

31. Papa, R.; Galderisi, A.; Vigo Majello, M.C.; Saretta, E. Smart and Resilient Cities. A Systemic Approach for Developing Cross-Sectoral Strategies in the Face of Climate Change. TeMA J. L. Use Mobil. Environ. 2015, 8, 19-49. [CrossRef]

32. Meerow, S.; Newell, J.P. Urban Resilience for Whom, What, When, Where, and Why? Urban Geogr. 2016, 40, 309-329. [CrossRef]

33. Davoudi, S.; Shaw, K.; Haider, L.J.; Quinlan, A.E.; Peterson, G.D.; Wilkinson, C.; Fünfgeld, H.; McEvoy, D.; Porter, L. Resilience: A Bridging Concept or a Dead End? "Reframing" Resilience: Challenges for Planning Theory and Practice Interacting Traps: Resilience Assessment of a Pasture Management System in Northern Afghanistan Urban Resilience: What Does It Mean in Planning. Plan. Theory Pract. 2012, 13, 299-333. [CrossRef]

34. Rocchetta, S.; Mina, A. Technological Coherence and the Adaptive Resilience of Regional Economies. Reg. Stud. 2019, 53, 1421-1434. [CrossRef]

35. Bång, M.; Rankin, A.; Radianti, J.; Brage, J.; Rosenqvist, S.; Lundberg, J.; Hernantes, J.; Sainz, M.; Eden, C. Multidisciplinary Literature Synthesis; Smart Mature Resilience Project; D1.3; Linköping University: Linköping, Sweden, 2016.

36. Almoghathawi, Y.; Barker, K.; Albert, L.A. Resilience-Driven Restoration Model for Interdependent Infrastructure Networks. Reliab. Eng. Syst. Saf. 2019, 185, 12-23. [CrossRef]

37. Longstaff, P.H.; Koslowski, T.G.; Geoghegan, W. Translating Resilience: A Framework to Enhance Communication and Implementation. In Proceedings of the 5th Resilience Engineering International Symposium, Soesterberg, The Netherlands, 25-27 June 2013.

38. Forsyth, T. Is Resilience to Climate Change Socially Inclusive? Investigating Theories of Change Processes in Myanmar. World Dev. 2018, 111, 13-26. [CrossRef]

39. Kuhn, T.S. The Structure of Scientific Revolutions, 11th ed.; Georgakopoulos, G.; Kalfas, V., Translators; Contemporary Issues: Athens, Greece, 2008; (Original work published in 1962).

40. Wang, J.W.; Gao, F.; Ip, W.H. Measurement of Resilience and Its Application to Enterprise Information Systems. Enterp. Inf. Syst. 2010, 4, 215-223. [CrossRef]

41. Deal, B.; Pan, H.; Pallathucheril, V.; Fulton, G. Resilience and Planning Support Systems: The Need for Sentience. J. Urban Technol. 2017, 24, 29-45. [CrossRef]

42. Amir, S.; Kant, V. Sociotechnical Resilience: A Preliminary Concept. Risk Anal. 2018, 38, 8-16. [CrossRef]

43. Ferreira, P.; Bellini, E. Managing Interdependencies in Critical Infrastructures-A Cornerstone for System Resilience. In Safety and Reliability-Safe Societies in a Changing World; Haugen, S., Barros, A., van Gulijk, C., Kongsvik, T., Vinnem, J.E., Eds.; Taylor \& Francis Group: Trondheim, Norway, 2018; pp. 2687-2692. [CrossRef]

44. UoW. Development of the Methodological Framework of the European Resilience Management Guidance (ERMG); RESILENS Project; D3.1; University of Warwick: Coventry, UK, 2016.

45. Vollmer, M.; Walther, G.; Jovanović, A.; Schmid, N.; Øien, K.; Grøtan, T.O.; Choudhary, A.; Kokejl, R.; Buhr, K.; Karlsson, A.; et al. Initial Framework for Resilience Assessment; SmartResilience Project; D1.1; EU-VRi: Stuttgart, Germany, 2016.

46. Alavi, A.H.; Jiao, P.; Buttlar, W.G.; Lajnef, N. Internet of Things-Enabled Smart Cities: State-of-the-Art and Future Trends. Measurement 2018, 129, 589-606. [CrossRef]

47. Ospina, A.V.; Heeks, R. RESILIENCE ASSESSMENT BENCHMARKING AND IMPACT TOOLKIT (RABIT) IMPLEMENTATION HANDBOOK; Version 1; University of Manchester: Manchester, UK, 2016.

48. Sebag, C. Cities of the Future: From Smart Cities to Resilient Cities. Available online: https://resiliencepoort.nl/from-smartcities-to-resilient-cities / (accessed on 20 March 2019).

49. ICLEI. Resilient Cities Report 2018 Tracking Local Progress on the Resilience Targets of SDG 11. In Proceedings of the 9th Global Forum on Urban Resilience and Adaptation, Bonn, Germany, 26-28 April 2018.

50. Faturechi, R.; Levenberg, E.; Miller-Hooks, E. Evaluating and Optimizing Resilience of Airport Pavement Networks. Comput. Oper. Res. 2014, 43, 335-348. [CrossRef]

51. Naser, M.Z.; Kodur, V.K.R. Cognitive Infrastructure-A Modern Concept for Resilient Performance under Extreme Events. Autom. Constr. 2018, 90, 253-264. [CrossRef]

52. Vaništa Lazarević, E.; Keković, Z.; Antonić, B. In Search of the Principles of Resilient Urban Design: Implementability of the Principles in the Case of the Cities in Serbia. Energy Build. 2018, 158, 1130-1138. [CrossRef]

53. Pires Ribeiro, J.; Barbosa-Povoa, A. Supply Chain Resilience: Definitions and Quantitative Modelling Approaches-A Literature Review. Comput. Ind. Eng. 2018, 115, 109-122. [CrossRef]

54. Coaffee, J.; Therrien, M.-C.; Chelleri, L.; Henstra, D.; Aldrich, D.P.; Mitchell, C.L.; Tsenkova, S.; Rigaud, É. Urban Resilience Implementation: A Policy Challenge and Research Agenda for the 21st Century. J. Contingencies Cris. Manag. 2018, 26, 403-410. [CrossRef] 
55. Elmqvist, T.; Andersson, E.; Frantzeskaki, N.; McPhearson, T.; Olsson, P.; Gaffney, O.; Takeuchi, K.; Folke, C. Sustainability and Resilience for Transformation in the Urban Century. Nat. Sustain. 2019, 2, 267-273. [CrossRef]

56. Sharpe, J.; Swartling, Å.G.; Pelling, M.; Pearson, L. Social Learning and Resilience Building in the EmBRACE Framework. In Framing Community Disaster Resilience; Deeming, T., Fordham, M., Kuhlicke, C., Pedoth, L., Schneiderbauer, S., Shreve, C., Eds.; John Wiley \& Sons, Ltd.: Chichester, UK, 2018; pp. 43-59. [CrossRef]

57. Wynne, L.; Riedy, C. Precinct-Scale Innovation and the Sharing Paradigm. In Building Urban Resilience through Change of Use; Wilkinson, S., Remøy, H., Eds.; John Wiley \& Sons, Ltd.: Chichester, UK, 2018; pp. 21-37. [CrossRef]

58. Krellenberg, K.; Koch, F.; Kabisch, S. Urban Sustainability Transformations in Lights of Resource Efficiency and Resilient City Concepts. Curr. Opin. Environ. Sustain. 2016, 22, 51-56. [CrossRef]

59. Muñoz-Erickson, T.A.; Campbell, L.K.; Childers, D.L.; Grove, J.M.; Iwaniec, D.M.; Pickett, S.T.A.; Romolini, M.; Svendsen, E.S. Demystifying Governance and Its Role for Transitions in Urban Social-Ecological Systems. Ecosphere 2016, 7, e01564. [CrossRef]

60. Antrobus, D. Smart Green Cities: From Modernization to Resilience? Urban Res. Pract. 2011, 4, 207-214. [CrossRef]

61. Randers, J.; Rockström, J.; Stoknes, E.; Golüke, U.; Collste, D.; Cornell, S. Transformation Is Feasible; Stockholm Resilience Center: Stockholm, Sweden, 2018.

62. Jabareen, Y. Planning the Resilient City: Concepts and Strategies for Coping with Climate Change and Environmental Risk. Cities 2013, 31, 220-229. [CrossRef]

63. Linkov, I.; Eisenberg, D.A.; Plourde, K.; Seager, T.P.; Allen, J.; Kott, A. Resilience Metrics for Cyber Systems. Environ. Syst. Decis. 2013, 33, 471-476. [CrossRef]

64. Ayyub, B.M. Systems Resilience for Multihazard Environments: Definition, Metrics, and Valuation for Decision Making. Risk Anal. 2014, 34, 340-355. [CrossRef]

65. Quinlan, A.E.; Berbés-Blázquez, M.; Haider, L.J.; Peterson, G.D. Measuring and Assessing Resilience: Broadening Understanding through Multiple Disciplinary Perspectives. J. Appl. Ecol. 2016, 53, 677-687. [CrossRef]

66. Buchmann, M. Emergent Properties. International Encyclopedia of the Social E Behavioral Sciences; Pergamon Press: Oxford, UK, 2001; pp. 4424-4428. [CrossRef]

67. Hofer, J.; Karapidis, A.; Hamann, K.; Bernd, D.; Dinesen, C.; Vinther-Larsen, L. Report on Risk Perception; Driver+ Project; D32.1; ISTUTT: Stuttgart, Germany, 2014.

68. Parks, D.; Rohracher, H. From Sustainable to Smart: Re-Branding or Re-Assembling Urban Energy Infrastructure? Geoforum 2019, 100, 51-59. [CrossRef]

69. Colding, J.; Barthel, S. The Potential of 'Urban Green Commons' in the Resilience Building of Cities. Ecol. Econ. 2013, 86, 156-166. [CrossRef]

70. Kummitha, R.K.R. Entrepreneurial Urbanism and Technological Panacea: Why Smart City Planning Needs to Go beyond Corporate Visioning? Technol. Forecast. Soc. Chang. 2018, 137, 330-339. [CrossRef]

71. Correira, L.; Wünstel, K. Smart Cities Applications and Requirements; Técnico Lisboa: Lisbon, Portugal, 2011.

72. Kumar, H.; Singh, M.K.; Gupta, M.P.; Madaan, J. Moving towards Smart Cities: Solutions That Lead to the Smart City Transformation Framework. Technol. Forecast. Soc. Chang. 2020, 153, 1-16. [CrossRef]

73. Camboim, G.F.; Zawislak, P.A.; Pufal, N.A. Driving Elements to Make Cities Smarter: Evidences from European Projects. Technol. Forecast. Soc. Chang. 2019, 142, 154-167. [CrossRef]

74. Escolar, S.; Villanueva, F.J.; Santofimia, M.J.; Villa, D.; del Toro, X.; López, J.C. A Multiple-Attribute Decision Making-Based Approach for Smart City Rankings Design. Technol. Forecast. Soc. Chang. 2019, 142, 42-55. [CrossRef]

75. Leydesdorff, L.; Deakin, M. The Triple-Helix Model of Smart Cities: A Neo-Evolutionary Perspective. J. Urban Technol. 2011, 18, 53-63. [CrossRef]

76. ISO/IEC. Information Technology ISO/IEC JTC 1 Smart Cities; ISO: Geneva, Switzerland, 2015.

77. Viitanen, J.; Kingston, R. Smart Cities and Green Growth: Outsourcing Democratic and Environmental Resilience to the Global Technology Sector. Environ. Plan. A 2014, 46, 803-819. [CrossRef]

78. Engelbert, J. Reading the Neoliberal Smart City Narrative: The Political Potential of Everyday Meaning-Making. In The Right to the Smart City; Cardullo, P., Di Feliciantonio, C., Kitchin, R., Eds.; Emerald Publishing Limited: Bingley, UK, 2019 ; pp. 43-55. [CrossRef]

79. Ismagilova, E.; Hughes, L.; Dwivedi, Y.K.; Raman, K.R. Smart Cities: Advances in Research—An Information Systems Perspective. Int. J. Inf. Manag. 2019, 47, 88-100. [CrossRef]

80. Angelidou, M. Smart Cities: A Conjuncture of Four Forces. Cities 2015, 47, 95-106. [CrossRef]

81. Caragliu, A.; Del Bo, C.F. Smart Innovative Cities: The Impact of Smart City Policies on Urban Innovation. Technol. Forecast. Soc. Chang. 2019, 142, 373-383. [CrossRef]

82. Barns, S. Smart Cities and Urban Data Platforms: Designing Interfaces for Smart Governance. City Cult. Soc. 2018, 12, 5-12. [CrossRef]

83. Mora, L.; Deakin, M.; Reid, A. Combining Co-Citation Clustering and Text-Based Analysis to Reveal the Main Development Paths of Smart Cities. Technol. Forecast. Soc. Chang. 2019, 142, 56-69. [CrossRef]

84. Ahvenniemi, H.; Huovila, A.; Pinto-Seppä, I.; Airaksinen, M. What Are the Differences between Sustainable and Smart Cities? Cities 2017, 60, 234-245. [CrossRef] 
85. Nilssen, M. To the Smart City and beyond? Developing a Typology of Smart Urban Innovation. Technol. Forecast. Soc. Chang. 2019, 142, 98-104. [CrossRef]

86. Andreani, S.; Kalchschmidt, M.; Pinto, R.; Sayegh, A. Reframing Technologically Enhanced Urban Scenarios: A Design Research Model towards Human Centered Smart Cities. Technol. Forecast. Soc. Chang. 2019, 142, 15-25. [CrossRef]

87. Martin, C.; Evans, J.; Karvonen, A.; Paskaleva, K.; Yang, D.; Linjordet, T. Smart-Sustainability: A New Urban Fix? Sustain. Cities Soc. 2019, 45, 640-648. [CrossRef]

88. Kunzmann, K.R. Smart Cities: A New Paradigm of Urban Development. CRIOS Critiwues 2014, 7, 9-19.

89. Kitchin, R. Towards a Genuinely Humanizing Smart Urbanism. In The Right to the Smart City; Cardullo, P., Di Feliciantonio, C., Kitchin, R., Eds.; Emerald Publishing Limited: Bingley, UK, 2019; pp. 193-204. [CrossRef]

90. Komninos, N.; Kakderi, C.; Panori, A.; Tsarchopoulos, P. Planning from an Evolutionary Perspective. J. Urban Technol. 2019, 26, 3-20. [CrossRef]

91. FIEC. Construction Manifesto for Action; EU Term 2019-2024; FIEC: Brussels, Belgium, 2019; p. 4.

92. EUROCITIES. EUROCITIES STRATEGIC FRAMEWORK 2014-2020; EUROCITIES: Brussels, Belgium, 2016.

93. Trindade, E.P.; Farias Hinnig, M.P.; Moreira Da Costa, E.; Sabatini Marques, J.; Cid Bastos, R.; Yigitcanlar, T. Sustainable Development of Smart Cities: A Systematic Review of the Literature. J. Open Innov. Technol. Mark. Complex. 2017, 3, 1-14. [CrossRef]

94. Trencher, G. Towards the Smart City 2.0: Empirical Evidence of Using Smartness as a Tool for Tackling Social Challenges. Technol. Forecast. Soc. Chang. 2019, 142, 117-128. [CrossRef]

95. Allam, Z.; Dhunny, Z.A. On Big Data, Artificial Intelligence and Smart Cities. Cities 2019, 89, 80-91. [CrossRef]

96. World Bank. Building Urban Resilience; Jha, A., Miner, T., Stanton-Geddes, Z., Eds.; World Bank: Washington, DC, USA, 2013. [CrossRef]

97. Ganin, A.A.; Mersky, A.C.; Jin, A.S.; Kitsak, M.; Keisler, J.M.; Linkov, I. Resilience in Intelligent Transportation Systems (ITS). Transp. Res. Part C Emerg. Technol. 2019, 100, 318-329. [CrossRef]

98. Kaklauskas, A.; Lill, I.; Amaratunga, D.; Ubarte, I. Model for Smart, Self-Learning and Adaptive Resilience Building. In 10th Nordic Conference on Construction Economics and Organization (Emerald Reach Proceedings Series, Volume 2); Lill, I., Witt, E., Eds.; Emerald Publishing Limited: Bingley, UK, 2019; pp. 315-324. [CrossRef]

99. Barker, K.; Lambert, J.H.; Zobel, C.W.; Tapia, A.H.; Ramirez-Marquez, J.E.; Albert, L.; Nicholson, C.D.; Caragea, C. Defining Resilience Analytics for Interdependent Cyber-Physical-Social Networks. Sustain. Resilient Infrastruct. 2017, 2, 59-67. [CrossRef]

100. Estevez, E.; Lopes, N.V.; Janowski, T. Smart Sustainable Cities. Reconnaissance Study; UNU Publications: Tokyo, Japan, 2016.

101. White, J.M. Anticipatory Logics of the Smart City's Global Imaginary. Urban Geogr. 2016, 37, 572-589. [CrossRef]

102. Gazzola, P.; Del Campo, A.G.; Onyango, V. Going Green vs Going Smart for Sustainable Development: Quo Vadis? J. Clean. Prod. 2019, 214, 881-892. [CrossRef]

103. ITU-T. An Overview of Smart Sustainable Cities and the Role of Information and Communication Technologies; ITU-T Publications: Geneva, Switzerland, 2014.

104. Marsal-Llacuna, M.-L.; Segal, M.E. The Intelligenter Method (I) for Making "Smarter" City Projects and Plans. Cities 2016, 55, 127-138. [CrossRef] 